Mir Sánchez, Elena.

Investigador, Facultad San Carlos de Valencia, Departamento de Escultura, Artes Visuales e intermedia.

\title{
La piel de la luz. Un camino a la inmaterialidad de los soportes de proyección.
}

\section{The skin of the light. A way to the immateriality of the projection support.}

TIPO DE TRABAJO:

Comunicación.

PALABRAS CLAVE:

Imagen-luz, soportes de proyección, instalación, multimedia.

KEY WORDS:

Image-light, projection supports, installation, multimedia.

\section{RESUMEN.}

Dentro de los sistemas de presentación desarrollados en el arte contemporáneo, el avance tecnológico ha actuado como desencadenante en la expansión a nuevos significados, materiales y usos de la luz. Los soportes de proyección como piel material, han evolucionado gracias a la hibridación con otras disciplinas, ampliando sus conceptos iniciales a nuevas posibilidades desde la instalación hasta las últimas manifestaciones actuales. De esta hibridación del arte junto a otras disciplinas tecnológicas, han surgido nuevos lenguajes, poéticas y materiales, con la consecuente creación de soportes de proyección cada vez más invisibles ó inmateriales. En esta presentación abriremos camino al conocimiento de los lenguajes artísticos multimedia interactivos, aplicados a soportes o pantallas de proyección capaces de reflejar luz, y de su evolución junto a los avances, descubrimientos e investigaciones científicas y tecnológicas, y otras disciplinas artísticas que se están desarrollando en la actualidad.

\section{ABSTRACT.}

Among all presentation models developed by contemporary art, the technological advance has acted as a trigger in the expansion of new meanings, materials and uses of light. The projection supports like material skin of light, have evolved thanks to the hybridization with other disciplines, extending their initial concepts to new possibilities from the installation to the latest manifestations today. From this hybridization of art along with other technological disciplines, new languages, poetics and materials have emerged, with the consequent creation of ever more invisible or immaterial projection supports. In this presentation we will open the way to the knowledge of interactive multimedia artistic languages, applied to projection supports or screens capable of reflecting light, and their evolution along with advances, discoveries and scientific and technological research, and other artistic disciplines that are being developed nowadays. 
CONTENIDO.

Tu primera palabra ha sido: Luz, y el tiempo fue. Después callaste largo rato. Rainer Maria Rilke.

Todo comienza en la luz. En ella se crea todo acto de comunicación y percepción. Estamos hechos en la luz y precisamente en ella, somos. En la luz todo fluye, pues es en sí misma movimiento, transcurrir que comprende de espacios y tiempos, y todo lo visible está allí donde abarca su halo, lejos de la oscuridad. De hecho, que la primera palabra fuera luz, no sería difícil de creer, pues el hombre ha construido su realidad en base a la evidencia visible del mundo, de lo que se encuentra delante de sus ojos, en la experiencia de aquellos espacios inundados por la luz. La luz, por tanto, ha actuado como un interruptor entre el hombre y el mundo, activando nuestros sentidos, generando realidades y perspectivas, formas de ver y entender nuestro entorno. Es por eso, que trabajar con luz requiere tener conciencia de la importancia de su manifestación. Sin ella no podríamos tener constancia de la realidad, pues solo ella encierra el enigma de la visión y sin ella seríamos ciegos ante el espacio circundante. La luz ha servido en todos los tiempos y ámbitos para dilucidar una nueva forma de entender el espacio y el entorno, aunque en esto también influyen aspectos fuera de la percepción como la cultura y la sociedad. La luz establece diálogos con el espacio que habita, y también con el tiempo de nuestra mirada, que aprecia los detalles en las gradaciones de la luz a la sombra. Aquellos artistas que emplean la luz como materia o material saben que trabajar con un elemento así implica conceptos filosóficos, simbólicos, perceptivos y, por supuesto, tecnológicos.

Por su parte el soporte, como lugar y espacio físico en el que poder materializar la imagen-luz, ha ido variando a lo largo del transcurso de la historia, desde las primeras proyecciones que ya se evidenciaron en las paredes de las cavernas y en las telas y papeles de arroz de las sombras chinescas, pasando, por la cámara oscura y la lámpara mágica, que serán los primeros mecanismos de proyección cuyo uso se limitaba a lienzos o a expresiones más teatrales, acabando con la aparición del cinematógrafo, como principal elemento proyectivo.

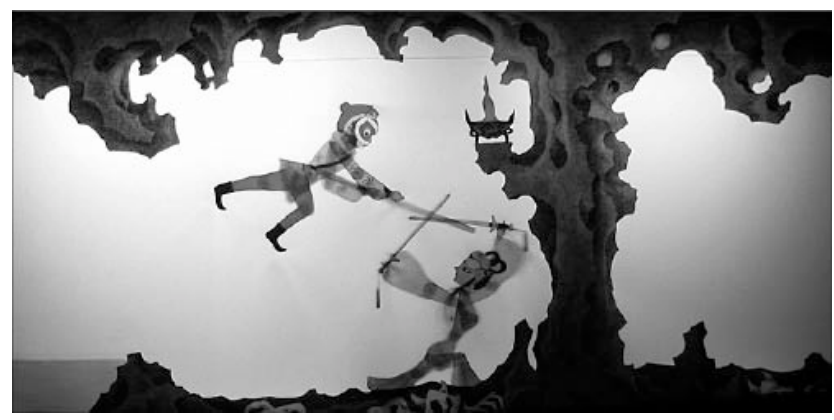

Sombras chinescas de la compañía Hong Kong Puppet \& Shadow Art Center.

La historia de las pantallas al igual que la historia del cine están estrechamente unidas. El cine es literalmente la historia de las luces y las sombras, proyectadas para conseguir crear una ilusión. Esas luces y sombras trasladadas a un soporte, sea éste opaco, traslúcido o transparente, se convirtieron en una forma de expresión en la que el hombre ha sentido aglutinar el mundo real en un espacio mágico, un lugar en el que poder contar sus propias historias, un lugar de experiencia e investigación. En palabras de Israel Márquez:

En este sentido, podría decirse que la pantalla cinematográfica es también una pantalla hipnagógica, un dispositivo capaz de sumirnos en un estado de tales características, donde los límites de lo real y el sueño se difuminan y no sabemos realmente si estamos soñando o siguiendo la película ${ }^{1}$.

El fenómeno de la proyección desde su aparición hasta la actualidad ha ido creando una nueva conciencia sobre los soportes, que, con el tiempo y fruto de la experiencia e investigación, ha dado como resultado el uso de materiales inéditos con cualidades capaces de crear profundidad, tridimensionalidad e incluso imágenes holográficas. En esta unión indisoluble entre la luz y su forma de materializarse, observamos como todo un legado de artistas que han incorporado la proyección a sus obras, siendo legado de un estudio absoluto de las pantallas.

${ }^{1}$ MÁRQUEZ, I. (2015, p. 24). 
Así pues, ha sido voraz la evolución en el uso de los soportes de proyección, sobretodo en sus manifestaciones físicas y plásticas, constatando las innovaciones que las nuevas tecnologías han añadido al arte y sus discursos. Es importante dotar de sentido al concepto inmersión para entender el interés asociado a la búsqueda de una apropiación espacial del entorno, que desde los orígenes ha buscado envolver o insertar al hombre en el espacio y en el tiempo, fruto de la experiencia, que será la que dé sentido al origen de los entornos inmersivos en experiencias como la realidad virtual, la realidad aumentada, el video mapping y los soportes interactivos. También el análisis de todas estas experiencias en relación con las pantallas y multipantallas, con respecto a la relación objetual y proyectiva, al igual que la sonora e interactiva. La creación espontánea de conceptos sociales y políticos innatos en aquellas manifestaciones que se presentan en el espacio público y en el paisaje, formando parte de la arquitectura y del entorno natural. Las relaciones con el cuerpo como soporte, y la gestualidad e interacción como medio expresivo junto a técnicas multimedia. Las nuevas manifestaciones y sus nuevas fronteras todavía lejos de clasificaciones y en constante expansión, descubriéndose en estos soportes hídridos entre arte y ciencia. Entendiendo, por tanto, el sentido de la imagen-tecnológica, como un nuevo significado expandido de la imagen-luz y de la imagen-movimiento. También hay que prestar atención a los bordes que desdibujan los límites, a veces difusos, entre el artificio y el arte, donde puede resultarnos difícil discernir entre lo lúdico y lo ilusorio de estos trabajos en la búsqueda de un fin expresivo. Sin embargo, sus límites se acaban por perfilar cuando vemos que los medios materiales no son fines en mismos sino un hilo conductor de estas nuevas formas de expresión. Tal y como nos explica José Luis Brea:

No todo desarrollo tecnológico, por lo tanto, da lugar a una forma artística. Pero toda forma artística nace irreversiblemente ligada a un desarrollo de lo técnico, a un estado epocal del mundo, del darse, del ser como espíritu, como constelación o sistema de partes ${ }^{2}$.

De las reflexiones de Brea entendemos, por tanto, que una forma artística que surge o se relaciona partiendo de un desarrollo tecnológico, lo hace aportando una experiencia novedosa de la representación pensada no en términos de identidad, sino en términos de diferencia, de diferición ${ }^{3}$. Es así que identifica esta emergencia como un nuevo orden de la representación cuya potencia es incalculable.

Desde este punto de partida, vamos a ver y entender la realidad que aportan los soportes, buscando entre estas formas híbridas de representación que permiten el surgimiento de nuevas formas de expresión que todavía no han encontrado límites, indagando finalmente en la superficie que consigue dotar de un sentido estético a estas nuevas formas de expresión, comprendiendo y analizando sus significados.

\section{El objeto como soporte de proyección.}

Una de las opciones más utilizadas como soporte para muchos artistas, es el empleo de objetos que sirven de material de proyección. El soporte-objeto en estos casos, se ve cada vez más desdibujado en su contacto directo con las proyecciones, convirtiéndose y adaptándose hasta tal punto, en que es indisoluble la realidad física de las proyecciones que se sobrescriben a estos objetos. Aquí el concepto de inmaterialidad, es un elemento afín, no solo desde el punto de vista material, sino también desde el conceptual y visual cuando observamos trabajos en los que se consigue un todo coherente, que involucra imagen y objeto en un solo punto de convergencia, tan preciso, que los límites de la realidad dejan de tener sentido, y el objeto se convierte en un nuevo ente completo, creando una nueva perspectiva de realidad de ese material. Por tanto, para muchos artistas, la esencia de inmaterialidad de los soportes, no solo transciende desde la presencia física inmaterial de los mismos, sino que se establece el concepto inmaterial desde una relación total e indisoluble del soporte y la proyección, siempre que estos formen un todo compacto. En este caso, se establece una relación multimedia, donde todos los elementos narrativos presentes: el objeto y su interacción con la imagen proyectada, expanden sus significados individuales a nuevos conceptos narrativos. La interacción objeto e imagen-luz generan una superposición de realidades, que modifican y reconstruyen el sentido final del objeto, amplificando sus significados originales. De esta forma se descontextualiza el objeto origen, que adquiere un significado plástico ligado al concepto de la obra.

Uno de los primeros artistas en utilizar objetos como soporte para conseguir modificar con ello la realidad, fue el artista Michael Naimark (Detroit, 1952) con su trabajo Displacements, 1980-2005. En la instalación, el artista recrea una habitación donde todos los objetos están inicialmente pintados de blanco, interpretando así todo el conjunto como una gran pantalla. La proyección que recae sobre todos estos elementos se ciñe a las volumetrías y contornos de los objetos, y los actores que aparecen en la proyección realizando actividades cotidianas se integran en el espacio vacío como si vivieran en él, dando sentido al concepto de lugar como un espacio que se llena de contenido a través de las experiencias y emociones. Una vez desaparecen las imágenes que interactúan de forma virtual con este espacio específico, la sensación del espectador es la de haber visto fantasmas que se integraban en la propia realidad.

\footnotetext{
${ }^{2}$ BREA, J. (1997).

3 lbídem.
} 


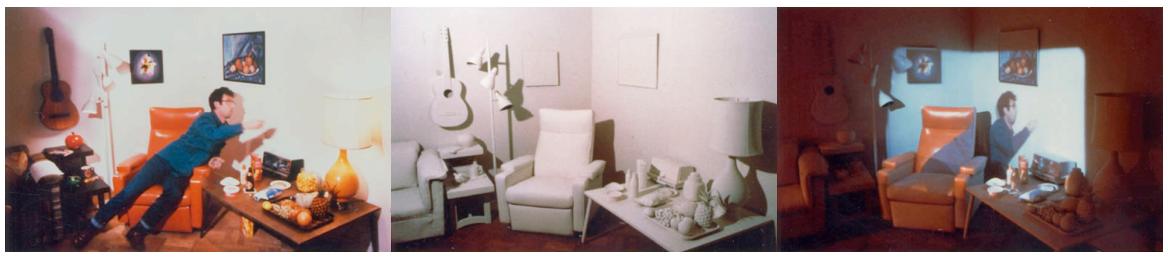

Michael Naimark. Displacements, 1980-2005.

La evolución material de este tipo de manifestaciones las encontramos actualmente en el video mapping, con proyecciones y visuales que se integran perfectamente al soporte físico del espacio sobre el que se proyectan. Los edificios, las plazas, los espacios ya existentes, las construcciones físicas creadas, se convierten en pantalla de proyección. Podemos ver en estas piezas como la intencionalidad final es la de integrar la proyección al espacio físico, siendo en muchos casos imposible diferenciar dicho efecto adscrito a la propia realidad física del soporte.

Uno de los ejemplos de este tipo de trabajos, lo encontramos en el colectivo de artistas alemanes UrbanScreen, que fusiona la arquitectura con el arte audiovisual, en una técnica llamada Lumentektur ${ }^{4}$ (combinación entre lumen -flujo de luminosidad- y arquitectura). Este concepto da un giro a la estática arquitectura tradicional, dándole vida con elementos y técnicas propias del teatro, el cine y el video. Uno de sus trabajos desarrollados para la fachada de la Galerie der Gegenwart en Hamburgo, con título How it would be, if house was dreaming, trata de una proyección sobre la propia fachada donde han jugado proyectando animaciones que provocan sensaciones muy reales: manos gigantes que se mueven y hunden en el muro, movimiento de bloques que parecen reales, las paredes se arrugan como si de papel se tratase.

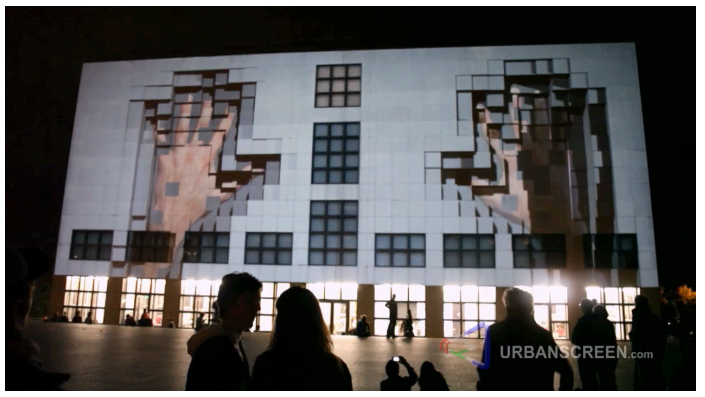

UrbanScreen. 555 Kubik. How it would be, if house was dreaming, 2009.

Sin duda otro artista referente en el empleo de objetos como lenguaje propio de su mundo particular, es el artista Tony Oursler (New York, 1957). En sus trabajos plantea la pantalla de forma volumétrica, de tal manera que, en sus instalaciones, entendidas como un conjunto de videoesculturas, consigue que sus proyecciones se ajusten a la morfología o volumetría de los objetos. El artista está interesado en la cara y en los gestos, y es por ello que construye personajes que se encuentran en una escena estática creada a partir de soportes volumétricos confeccionados con textil u otros materiales, donde las proyecciones que usualmente son caras, ojos, bocas o construcciones de todos ellos, se mueven y expresan sentimientos, incluso llegando a la incomodidad. Una representación bastante permanente en sus trabajos, es emplear tela rellena de guata para crear las caras vistiendo al personaje, y colocándolo en una disposición incómoda, por ejemplo, sillas que se apoyan sobre las cabezas, o debajo de muebles. En sus trabajos más recientes también proyecta sobre árboles, edificios y superficies especialmente diseñadas y calculadas para contener sus proyecciones. Es así que sus trabajos de luz contribuyen a generar una nueva percepción psicológica del espacio habitado. La morfología de las estructuras que construye para contener la proyección, son técnicamente el eje central de su innovación plástica.

\footnotetext{
${ }^{4}$ Lumentektur se trata de un proceso tecnológico registrado. A través de una medida exacta la proyección es adaptada de forma precisa a las instalaciones ó superficies donde se va a proyectar la animación. Esto proporciona una referencia directa a la interacción con el fondo.
} 

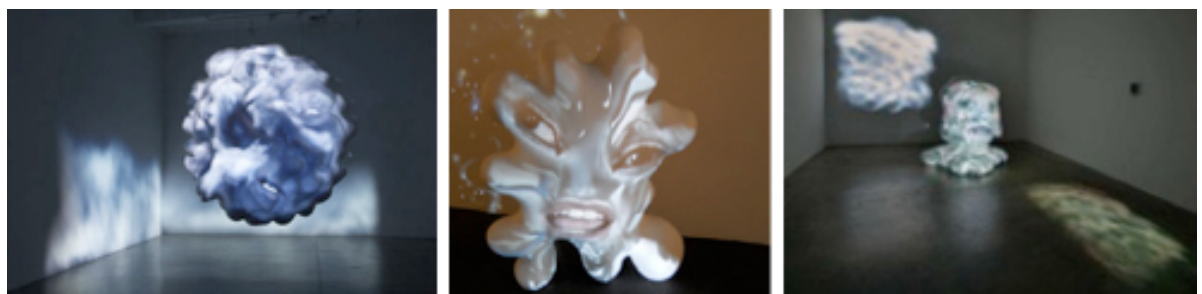

Tony Oursler. Thought forms, 2006.

Por su parte, otros objetos son empleados bajo una proyección intimista, como contenedores y recipientes de ideas, en muchos casos estableciendo una conexión íntima que se establece entre esos elementos y la proyección. Bachelard, nos habla de la expansión del espacio que se produce en los casos en los que conectamos "lo de dentro con lo de fuera", en la experiencia objetual y sus relaciones:

Dar su espacio poético a un objeto, es darle más espacio que el que tiene objetivamente, o para decir mejor, es seguir la expansión de su espacio íntimo ${ }^{5}$.

En este trabajo íntimo y profundo de relación con los objetos, encontramos la videoinstalación Flow de la artista Amy Jenkins (Peterborough, 1966). En una alegoría al acto de la creación (dar a luz), la artista con una fuerte influencia simbólica ligada al agua, que de nuevo según Bachelard, nos puede sugerir la vida, el nacimiento y el renacimiento, de la misma forma que contrariamente también nos puede sugerir la muerte y la pérdida en la entidad del agua como una fuerza destructora natural. En el video de nueve minutos, observamos a la artista en nueve momentos diferentes del transcurso de su embarazo, un minuto por cada estado. Su cuerpo en contacto con el agua, en un ritmo relajante y pausado, va cambiando hasta mostrar a la artista en la plenitud de su embarazo. La proyección que se realiza directamente sobre la superficie de una bañera en miniatura llena de agua, convirtiendo el objeto en soporte de proyección, nos muestra una relación directa del cuerpo en un espacio intimista de una mujer consigo misma en un estado de concepción de una nueva vida. La imagen oscilante del flujo del agua nos remite a la estancia en el útero materno.

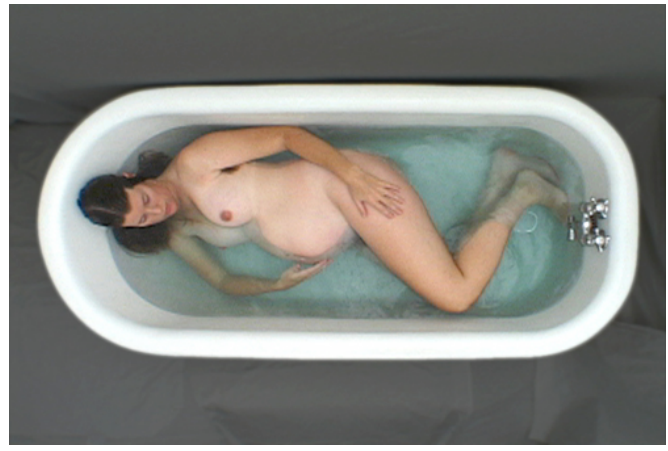

Amy Jenkins. Flow, 2005.

En otros trabajos, el soporte sobre el que se apoya la luz se convierte en habitáculo, en un espacio de interrelación del que surge un nuevo espacio que cobra vida dentro de la propia pantalla creando una realidad ficticia. El lenguaje minimalista y sencillo en la serie de trabajos con nombre Between de la artista Yiyun Kang (Korea, 1982), es sin duda un ejemplo de construcción de un espacio dentro del soporte. Las múltiples proyecciones y pantallas flotantes junto a la sutileza de las imágenes, convierten la instalación en un espacio en el que realidad y ficción se confunden. Las proyecciones muestran el residuo del trabajo de un performer sobre un tejido, de tal forma que estas imágenes al ser proyectadas sobre los lienzos flotantes, parecen realmente contener un individuo en su interior. Estas huellas hechas por el cuerpo, que tan sólo se sustentan en las luces y sombras creadas por su movimiento, difuminan la idea de realidad, jugando con nuestros sentidos. Este diálogo que se crea utilizando la alteración de la percepción, cuestiona nuestros límites sensoriales y nos sugiere la pantalla como un elemento contenedor, como un recipiente real, no solo proyectivo sino con capacidad para ser e ir más allá.

\footnotetext{
${ }^{5}$ BACHELARD, G. (1975, p. 178).
} 


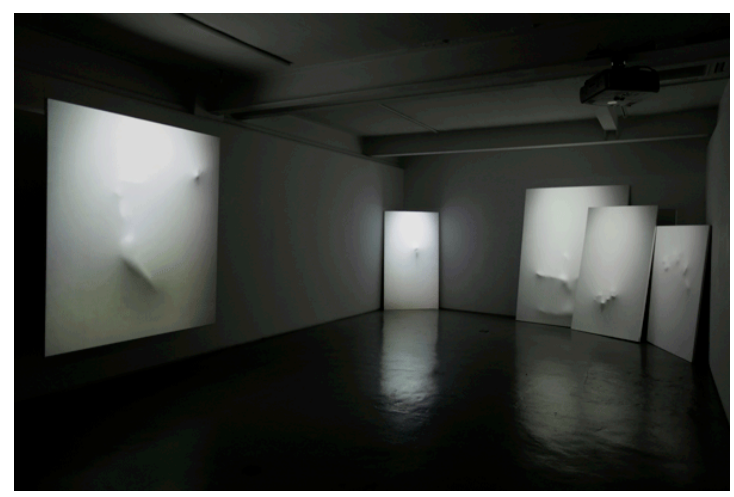

Yiyun Kang, In-between. 2009.

\section{El cuerpo como soporte.}

El cuerpo, de igual forma que cualquier otro material, también se ha convertido en soporte de proyección. Es el caso de disciplinas tan diversas como la danza, el teatro, el cine, la música, las artes visuales o la tecnología, que finalmente consiguen converger en una cohesión expresiva sin precedentes, dando lugar a producciones multimedia que funcionan a modo de experimento visual. Estas piezas evocan ideas en torno a la química, la biología, la enfermedad, el cuerpo como energía, la tecnología, software, datos, ordenadores, etc.

El trabajo Mortal Engine de Chunky Move, es un buen ejemplo de esta interrelación interdisciplinar entre cuerpo y tecnología. El coreógrafo australiano Gideon Obarzanek (Melbourne, 1966) ha creado una obra maestra de la integración entre máquina y cuerpo, utilizando las últimas tecnologías. Para ello ha contado con un gran equipo multidisciplinar compuesto por el diseñador de sistemas interactivos Frieder Weiss, el diseño de iluminación de Damien Cooper, y el láser y sonido de Robin Fox, dando como resultado un trabajo hipnótico y de una gran expresividad. En esta coreografía entre danza y audiovisuales, el cuerpo y su movimiento se convierten en el eje central del trabajo. Los artistas se muestran como organismos completamente envueltos por una perfecta segunda piel que es la proyección, que entra en simbiosis con cada uno de los movimientos y acciones que desarrollan. Los extremos de sus cuerpos son alcanzados por los elementos multimedia, que actúan como extensiones metafísicas de ellos mismos.

Las luces brillantes violentamente contrastantes, sus parpadeos, sus pulsos, producen en el espectador un estado de trance hipnótico. Un encuentro entre danza y multimedia que nos ofrece una perspectiva fascinante de lo ilimitado que es el uso de estos recursos, sobre todo cuando se desarrollan a la vez, en una perfecta armonía donde el medio digital y audiovisual actúan como una extensión del cuerpo, y todo funciona como una sola entidad. Estos efectos lumínicos están creados mediante programas de detección de movimiento, que están unidos a los pulsos de sonido que actúan como un monitor cardíaco, reaccionando a los cambios; y ésta es realmente la parte más compleja del trabajo, pues en esta ilusión realista debe existir una perfecta sintonía entre los movimientos y las proyecciones. Por tanto, Mortal Engine trata de una sinergia que fusiona disciplinas, creando un cóctel armónico que mezcla biología con tecnología, en un esfuerzo evocador e ilusionista.

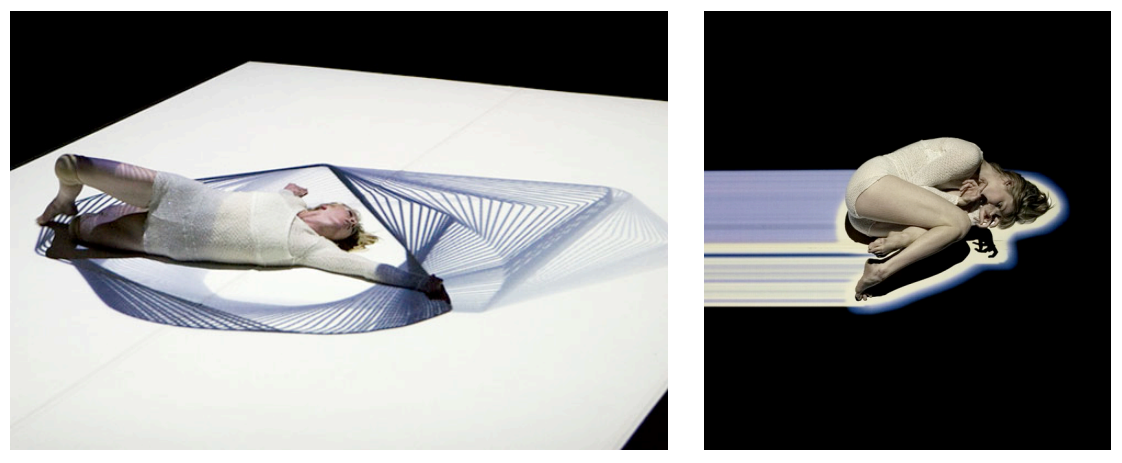

Fragmentos de Mortal Engine de Chunky Move, 2008. 
Por otro lado, dentro de las experiencias que podemos también encontrar en las aplicaciones del video mapping, encontramos trabajos que, utilizando el cuerpo como pantalla, pretenden modificar la realidad existente, pero creando una realidad aumentada espacial que se ciñe al cuerpo humano, tratándolo como un soporte de proyección capaz de convertirse en cualquier cosa. Es así como el artista Nobumichi Asai (Korea, 1968), con su trabajo Omote, palabra japonesa que significa máscara, nos seduce con un trabajo que explora las nuevas posibilidades de integración de la última tecnología y el arte japonés clásico.

El sistema en su conjunto fue creado por Paul Lacroix y Nobumichi Asai, cuya complejidad estriba en la dificultad de proyectar con seguimiento en tiempo real, algo que no se había hecho hasta este momento. Es por ello que tuvieron que empezar de cero capturando con sensores el procesamiento de los datos, la creación de renderizado $\mathrm{CG}^{6}$ (que se utiliza comúnmente en coches y edificios, pero nunca se había utilizado sobre una persona en movimiento) y el uso de proyectores.

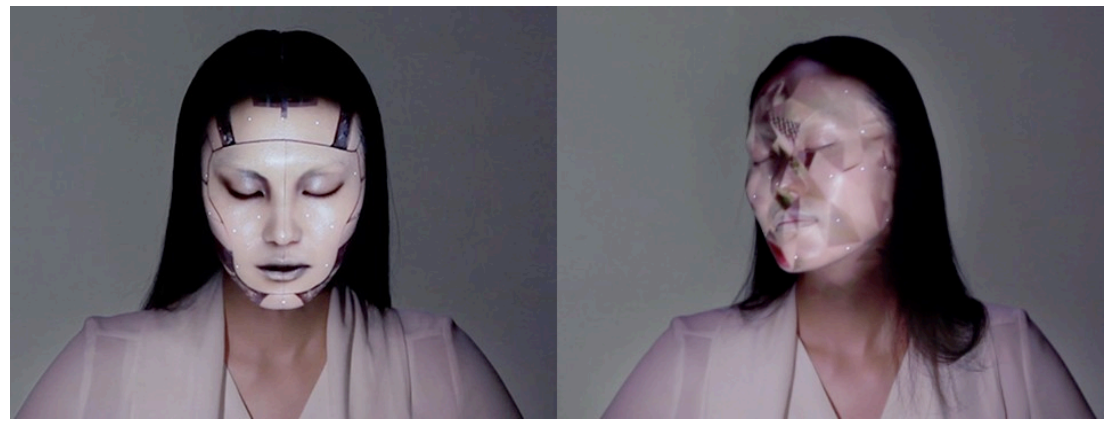

Nobumichi Asai. Omote, 2014.

Para ello utilizaron sensores OptiTrack de respuesta rápida, que realiza un escaneo del movimiento 3D, y desarrollaron un programa para reducir el tiempo de latencia, integrando todo el proceso en un solo programa. El resultado es un trabajo que técnicamente muestra una perfecta concordancia entre el cuerpo y la proyección, pareciendo ambos partes de una misma entidad. Es por eso que este trabajo establece un gran avance científico, pues el uso de las técnicas usadas en él es inédito.

Nuevamente apreciamos como todos estos trabajos integran la proyección tan fielmente al soporte, que ambos se disuelven en esa inmaterialidad aparente que se diluye ante la visión de apreciar una nueva realidad completa y coherente. Desde este punto de vista, por tanto, podemos considerar la inmaterialidad del soporte como una disolución de realidades que convergen en una nueva.

\section{MATERIALES INTANGIBLES: LA LUZ SIN SOPORTE.}

En todo arte hay una parte física que no puede contemplarse ni tratarse como antaño. Ni la materia, ni el espacio, ni el tiempo son desde hace veinte años lo que eran desde siempre. Hay que esperar que tan grandes novedades transformen toda la técnica de las artes y de ese modo actúen sobre el propio proceso de la invención, llegando quizás a modificar prodigiosamente la idea misma del arte ${ }^{7}$.

Tal y como decía Valéry, el arte se encuentra en constante reinvención ligado a los procesos y mecanismos tecnológicos de su tiempo. Es así que muchas investigaciones actuales giran en torno al uso de materiales intangibles para utilizarlos como pantalla de proyección, tanto en el campo del arte como en la ciencia. El uso de este tipo de soportes ha dado resultados inesperados de un gran valor científico por su capacidad de sostener la luz en el aire, expandiendo los sentidos propios de la imagen a nuevos lenguajes y narrativas artísticas. El empleo de estos materiales inverosímiles, deja constancia de la importancia que hoy en día tiene la búsqueda de un medio inmaterial sobre el que materializar la imagen.

Un ejemplo del uso de estos soportes inmateriales lo encontramos en el empleo del humo y el agua pulverizada, así como en los reflejos de espejos, las pantallas coloidales y en los soportes holográficos, que consiguen crear la ilusión de imágenes volátiles que se funden con el espacio. Estas obras etéreas permanecen sostenidas en el aire creando una sensación holográfica que juega con la percepción en una mezcla de realidad e ilusión. Un ejemplo de este tipo de proyecciones, similares a las fantasmagorías, que en su sentido poético aportan valores cercanos a lo místico e ilusorio.

\footnotetext{
${ }^{6}$ CG o C for Graphics, es un lenguaje de alto nivel desarrollado por Nvidia en colaboración con Microsoft, para la programación de tecnologías destinadas a efectos especiales, entre otros, y que emplean una tecnología que ha experimentado una gran evolución destinada a proporcionar al programador una interacción con la unidad de procesamiento gráfico, hasta ahora imposible.

${ }^{7}$ Ver "La conquista de la ubicuidad" (1928), en: VALÉRY, P. (1999, p. 131).
} 
El trabajo de Eugenio Ampudia (Valladolid, 1958), cuyas proyecciones etéreas y visualmente impactantes, las resuelve mediante un estudio del soporte. Es así que con su obra Chamán experimenta sobre superficies de proyección como el vapor de agua. En esta obra, la video-proyección que permanece volátil, genera una imagen de una calidad poética sobrecogedora, pero sobretodo, nos parece extraordinario e innovador el empleo del vapor de agua como soporte de la proyección de imagen-luz. En este trabajo de Ampudia la capacidad del agua de inmaterializar la imagen-luz nos ofrece una pseudo-realidad que adquiere matices de holograma.

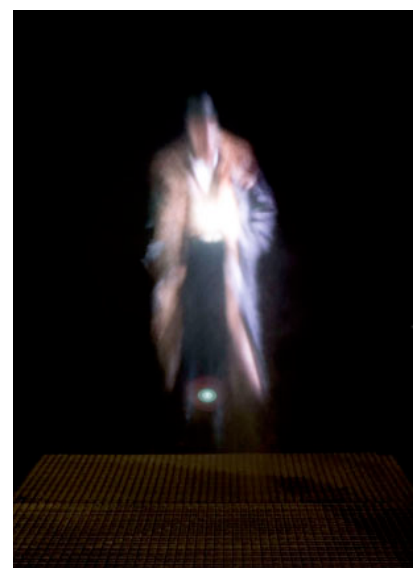

Eugenio Ampudia. Chamán, 2006.

Entre los procesos de hibridación tecnológica existentes en la actualidad, destaca la incrustación de unas imágenes en otras, la división o fragmentación de las pantallas y el uso de dispositivos como móviles o tabletas en las obras. Todas estas disposiciones y nuevos recursos establecen una nueva forma de enfrentarse al trabajo, aportando un carácter lúdico y recreativo a las obras. La magnífica y etérea sostenibilidad que los soportes translúcidos o transparentes han demostrado a la hora de contener la luz proyectada, ha adquirido en la actualidad un gran interés por parte del arte. Estos soportes confieren un aspecto de realismo a las instalaciones, creando efectos y poéticas que sugieren conceptos como: fragilidad, volatilidad, sutileza, etc., añadiendo cualidades perceptivas nuevas y mayores posibilidades de representación.

Dentro de los artistas que usan este tipo de soportes en la actualidad es destacable el trabajo de la artista Eugènia Ballcells (Barcelona, 1943) más allá de la amplia producción plástica que ha generado en torno a la instalación audiovisual y a la búsqueda de medios y materiales, su interés ha estado en la investigación en torno a soportes inmateriales. En su trabajo, Traspassar Límits, 1995, la artista mostró, por primera vez, una consecución de pantallas traslúcidas, paralelas, suspendidas en el espacio oscuro, de un tejido similar al tul o tejido muy ligero y microperforado. Dos proyecciones se enfrentan en las pantallas y las imágenes atraviesan todas las capas hasta encontrarse en el espacio central, confrontándose y fundiéndose unas en otras.

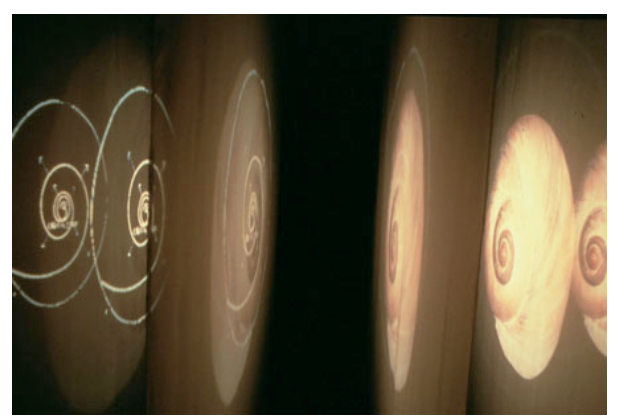

Eugènia Balcells, Traspassar Límits, 1995.

Por su parte, el artista Gints Gabrāns (Letonia, 1970), invita en sus obras al espectador a participar en experimentos perceptivos y cognitivos que revelan realidades invisibles a simple vista. Combina un lenguaje que, consciente del trasfondo cultural de la Europa del este basado en el poder, encuentra en la alquimia de diversos materiales el hilo conductor para crear conexiones místicas entre la ciencia y el pensamiento. En sus trabajos hace alusión a la energía producida a partir del interior (inconsciente) del ser humano. Es por eso que trata de hacer visible lo que no es, provocando la alteración de nuestra percepción. En su instalación Not a wave, not a corpuscle. Going through walls, realizada en la Iglesia Anglicana de Riga-Letonia, en 2008, nos sitúa ante un muro luminoso y nos invita a atravesarlo. Cuando el espectador cruza el muro y gracias a la luz focal que ilumina el perímetro del soporte, los bordes de éste 
aparecen iluminados. Una vez el usuario traspasa el muro, una proyección a modo de residuo físico de la persona que acaba de pasar, se volatiliza como una estela, como si se tratase de un ente espiritual o de un residuo inservible que se desvanece como el polvo en el aire.
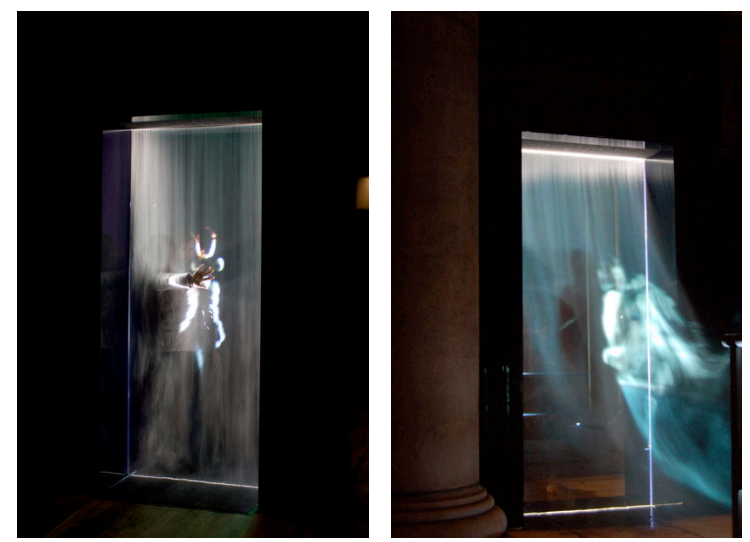

Gints Gabrāns. Not a wave, not a corpuscle. Going through walls, 2008.

Kimchi and Chips con su trabajo Light Barrier crean fantasmas de luz en el aire. Utilizando espejos convexos calibrados, algo de humo y una proyección, consiguen que la instalación de luz cree objetos gráficos que se animan en el espacio y en el tiempo. Gracias a su fascinación por la luz, han sido capaces de crear una nueva mecánica visual inédita, utilizando el propio espacio como único soporte proyectivo.

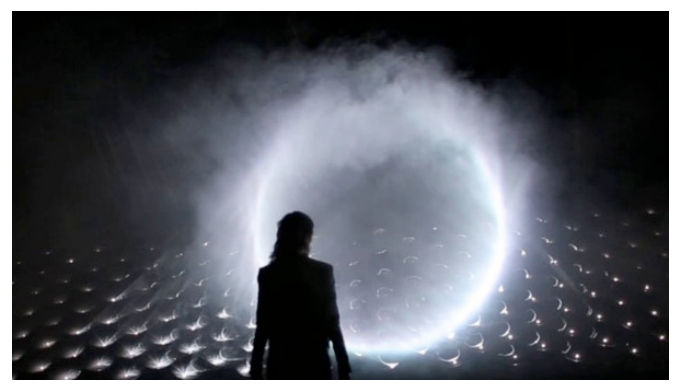

Kimchi and Chips, Light Barrier. 2014.

Otro descubriendo llevado a cabo por los investigadores de Computación Gráfica y Laboratorio de Geometría EPFL, son las proyecciones de luz que controlan el reflejo en superficies cáusticas ${ }^{8}$, consiguiendo que la luz reflejada sobre estas superficies, pueda ser controlada hasta el punto de recrear una imagen con la proyección que la luz emite de ellas. Gracias a un algoritmo elaborado, consiguieron dar forma a un objeto transparente que organiza de forma coherente la luz que se reflejaba sobre este y en consecuencia reproduce imágenes perfectamente reconocibles.

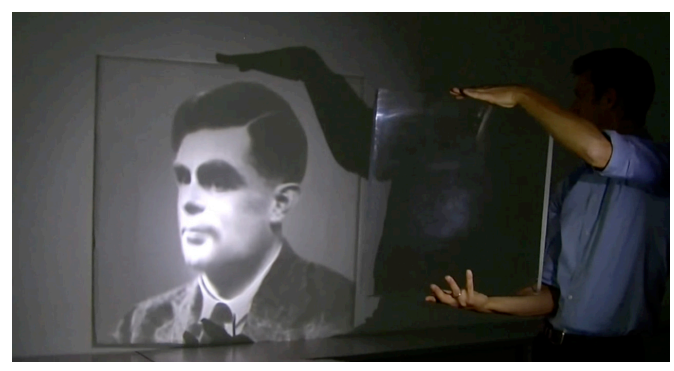

Reflexión cáustica de la luz con un soporte transparente elaborado mediante algoritmos.

\footnotetext{
${ }^{8}$ En óptica una superficie cáustica es aquella que es tangente a los rayos de luz que se reflejan sobre ella. Un ejemplo natural de este efecto lo encontramos en los reflejos producidos por las ondas del agua en una piscina.
} 
Dentro de las tecnologías emergentes, un equipo de científicos formado por Yoichi Ochiai, Alexis Oyama y Keisuke Toyoshima, crearon la pantalla coloidal (superficie como la de una pompa de jabón creada mediante la mezcla de líquidos coloidales), que propone una solución innovadora que transforma una película de jabón en la pantalla más delgada del mundo. La textura de esta pantalla transparente y su forma pueden controlarse mediante el uso de ondas sonoras ultrasónicas.

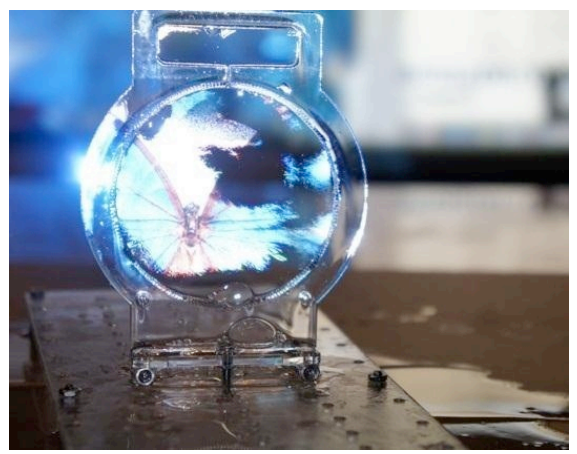

Pantalla coloidal.

\section{Dispositivos holográficos.}

Sin duda, una de las mayores preocupaciones actuales en cuanto a soportes se refiere, gira en torno a la creación de pantallas capaces de crear holografías ${ }^{9}$ y figuras tridimensionales que den la sensación de flotar en el espacio. Éstos, los llamados dispositivos Holográficos u Hológrafos (holographic display) son aquellos que utilizan los principios de la holografía para la reproducción de imágenes tridimensionales o pseudotridimensionales. Es una tecnología que no necesita de aparatos externos de visión (como gafas o cascos especiales) para reproducir imágenes tridimensionales. Otros sistemas de reproducción de imágenes tridimensionales son los sistemas estereoscópicos o los dispositivos volumétricos. Dentro de las líneas de investigación llevadas a cabo en la actualidad para la creación de de dispositivos holográficos, diferenciamos por el momento distintos soportes que clasificamos según su materialidad. Por un lado, encontramos holografías que se crean sobre soportes sólidos, otras cuyos soportes son volátiles, una tercera en la que el soporte es inmaterial y una última característica procedente del último estado conocido de la materia: el plasma.

El sistema Pro Display's Clearview es un ejemplo de este tipo de pantallas sólidas que ofrecen una alternativa de bajo coste en la competencia de pantallas holográficas, con un rendimiento superior, definición y sin ángulo crítico de proyección. Esta tecnología de pantalla de proyección permite la visibilidad a través de la pantalla, mientras que la visualización de las imágenes es brillante, nítida y vibrante. Disponible como una película autoadhesiva, o una pantalla de vidrio o acrílico, es un tipo de tecnología holográfica empleada por los museos, para eventos en vivo y lanzamientos de productos, por nombrar sólo algunos ejemplos. El resultado final es una holografía bidimensional, que crea efecto de flotabilidad.

Heliodisplay es una tecnología creada por la empresa IO2Technology que reproduce hologramas en dos dimensiones sin utilizar un medio físico como una pantalla. Permite proyectar una imagen estática o en movimiento con una cierta calidad, de unas 27 pulgadas de tamaño, sin utilizar medios alternativos como humo o agua, y puede ser utilizado en cualquier entorno sin instalaciones adicionales. Lo que se hace es convertir las propiedades del reflejo del aire. El aire se captura, se convierte de forma instantánea y se vuelve a expulsar. La imagen se proyecta sobre el aire convertido. Otra característica importante es que la imagen generada es interactiva., aunque la sensación de la imagen no es totalmente tridimensional, siendo la sensación 3D solo es frontal, ya que, visto de lado, la imagen se ve plana.

\footnotetext{
${ }^{9}$ La holografía fue un descubrimiento del físico húngaro Dennis Gabor en el año 1947. El origen de su investigación era encontrar una mejora en la resolución y definición de las imágenes del microscopio electrónico. Por su contribución teórica a las técnicas holográficas fue galardonado con el premio Nobel de Física en el año 1971.
} 


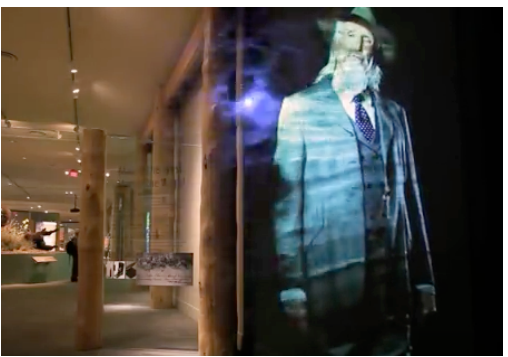

Ejemplo de pantalla Heliodisplay.

La compañía Displair, que recientemente mostró su máquina Display Air Touch System, una pantalla que utiliza micropartículas de agua como soporte de proyección. La máquina es interactiva y necesita ser conectada a un dispositivo de pantalla táctil. Tiene una cámara, un sensor, y un proyector para proyectar la pantalla hacia delante en la pared de niebla. A pesar de que la imagen se crea en el aire, se puede tocar físicamente e interactuar con ella.

Dentro de los soportes de proyección holográfica que consiguen crear proyecciones inmateriales, encontramos muchas empresas y equipos de investigación que se encuentran actualmente diseñando dispositivos para la creación de estas imágenes. Entre estos nuevos descubrimientos encontramos el dispositivo Cheoptics $360^{10}$, desarrollado por las empresas viZoo y Ramboll. Es un sistema de video holográfico que consiste en un proyector formado por una pirámide invertida que es capaz de generar imágenes tridimensionales dentro de su espacio de proyección. La imagen que proyecta se ve totalmente tridimensional desde cualquier ángulo de observación. Los proyectores que se sitúan en cada extremo del sistema, se combinan para generar la imagen en el centro, provocando una sensación de total realismo. Este invento puede proyectar imágenes desde 1,5 hasta 30 metros de altura con cualquier condición lumínica ambiental y reproducir imágenes procedentes de un ordenador.

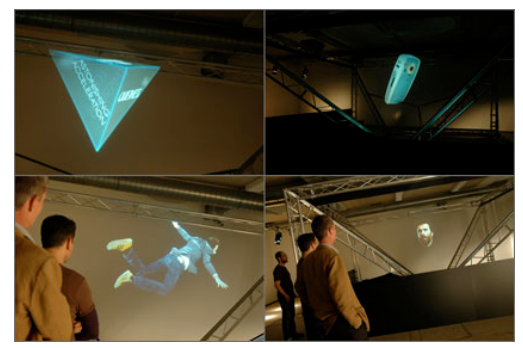

Imágenes de las holografías creadas con Cheoptics 360.

Por último, las proyecciones holográficas más recientes son las creadas mediante tecnología plasma láser. Esta tecnología permite la creación de hologramas tridimensionales, aunque de momento los gráficos que se pueden realizar son muy sencillos. La fuente de luz láser utilizada para este trabajo es de alta calidad. Consiste en un láser pulsado de infrarrojos de alto brillo, utilizado para que la producción de plasma se pueda controlar con mayor precisión, lo que permite dibujar imágenes sencillas mediante la sincronización de estos pulsos.

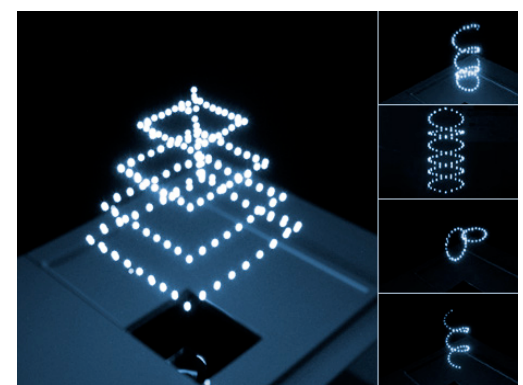

Imagen realizada con tecnología plasma láser.

\footnotetext{
${ }^{10}$ CHEOPTICS. Cheoptics hologram, <https://www.youtube.com/watch?v=YVIJwLgLkJ0> [Consulta: Octubre 2015].
} 


\section{La última pantalla.}

Es así que todas las investigaciones recientes en torno al estudio de las nuevas pantallas, se encaminan en trabajar los soportes desde su invisibilidad, eliminando perceptivamente la barrera de la pantalla como objeto e incorporando la tecnología en ellos, hasta tal punto, que quede insertada dentro de nuestra propia realidad. De la misma manera, otra línea busca la integración de la pantalla en nosotros mismos, en nuestro propio cuerpo, formando parte de un componente más de nuestro sistema perceptivo. De esta forma se produce un efecto de inmersión de nuestros sentidos que anula la tradicional diferenciación entre sujeto y objeto, entre el observador y lo observado. Jean Baudrillard ya vislumbró la llegada de este tipo de pantalla integrada en el propio cuerpo, cuando escribía sobre las nuevas tecnologías:

Como lentes de contacto, prótesis transparentes, como integradas en el cuerpo, hasta formar parte de él, casi genéticamente como estimuladores cardíacos ${ }^{11}$.

En este sentido, la tecnología cada vez permanece más atenta a incorporarse de una manera más intrínseca a nuestra realidad física y corpórea. Es así que Virilio señala que en el campo de la visión humana existe una tendencia a monitorizar y maquinizar nuestra percepción en lo que él llama endocolonización ${ }^{12}$, insertando la tecnología hasta tal punto dentro del cuerpo que llegue a confundirse con nuestra propia percepción del mundo, formando parte de nuestro sistema nervioso.

Por eso en un intento por vislumbrar lo que vendrá, observamos ese intento por convertir las pantallas en formatos completamente invisibles, insertados o no en nuestro cuerpo, estos soportes se convertirán en una segunda piel, actuando como una nueva realidad física del mundo, tan reales y palpables como nosotros mismos, como prótesis de nuestro cuerpo. Tal y como nos dice Israel Márquez: La gran aventura de la pantalla continúa en forma de innumerables secuelas que ya están siendo pensadas y elaboradas en centros de investigación de todo el mundo. Por equipos de investigadores e ingenieros que están dibujando los posibles nuevos dispositivos, tamaños, diseños, usos y aplicaciones de un objeto que se ha convertido por derecho propio en la principal prótesis de la sociedad contemporánea ${ }^{13}$.

A nivel general podemos concluir que los artistas, hoy en día, se encuentran vinculados cada vez de forma más activa en la hibridación de lenguajes, produciendo obras que requieren de una síntesis compleja entre arte, ciencia y tecnología, y dando lugar a encuentros donde la luz se posa sobre soportes cada vez más inmateriales, cuyo uso es muy significante y donde se construye no solo para alterar o producir un encuentro háptico que sirva de pegamento entre las partes, sino también porque los artistas construyen con este como soporte a través de su fisicidad. De esta manera, los soportes físicos de la luz son cada vez más ingrávidos, etéreos y volátiles.

Esa misma inexistencia del soporte, tiene una gran importancia actualmente para muchos artistas que precisan de esa carencia material a la hora de transmitir sus discursos, y hemos podido constatar que la ciencia y la hibridación de lenguajes están siendo muy fructíferos en la búsqueda de nuevos caminos para el desarrollo tecnológico y artístico.

Estos descubrimientos y procesos tecnológicos y científicos, han permitido ir de experiencias locales únicamente formuladas para usos técnicos evidenciando una clara interdisciplinariedad, que el arte ha conseguido reconducir para llevarlos a procesos mucho más complejos, aunando los esfuerzos y derivándolos a usos artísticos, consiguiendo llenar de nuevos significados y conceptos estas nuevas formas de expresión, promoviendo una forma de hacer multidisciplinar que requiere de conocimientos y áreas del saber muy diversas, pero interrelacionadas, sirviendo como motor que permite seguir investigando y descubriendo.

La utilización de un determinado material como soporte para la proyección, así como de su dimensión, disposición y volumetría, están sirviendo para dar sentido al fin último del trabajo, ayudando a transmitir conceptos y a tener una experiencia y sensación diferente, sobre todo cuando se trasladan al espacio en forma de instalación. Mirando la pantalla, finalmente, nos damos cuenta de la importancia del material sobre el que se proyecta. No es lo mismo una pantalla de tela opaca, que una tela traslúcida, no es igual proyectar sobre humo que sobre el agua pulverizada, no da igual si el soporte está perforado, o si su superficie es reflectante o incluso transparente. Nada tiene que ver proyectar sobre una bola de algodón, que sobre un árbol o un edificio o incluso sobre el propio cuerpo. Pues el discurso que se transcribe y sobreimprime a esa piel luminosa, es por sí mismo un recurso necesario que nos incita a acercarnos, a entrar en contacto con la obra, a entender más allá de su forma y contenido.

\footnotetext{
${ }^{11}$ BAUDRILLARD, J. (1990, p. 34).

${ }^{12}$ Conquista tecnocientífica del interior del cuerpo humano mediante la inserción subcutánea de componentes digitales. Ver en: VIRILIO, P.; LOTRINGER, S. (2008, p. 91-103).

${ }^{13}$ MÁRQUEZ, I. (2015, p. 244).
} 

http://dx.doi.org/10.4995/ANIAV.2017.5689

\section{FUENTES REFERENCIALES.}

BACHELARD, Gastón. 1975. La poética del espacio, México D.F.: Fondo de Cultura Económica.

BAUDRILLARD, Jean. 1990. Videosfera y sujeto fractal. En AAVV. Videoculturas de fin de siglo, Madrid: Cátedra.

BREA, José Luis. 1997. Nuevos soportes tecnológicos, nuevas formas artísticas. [Consulta: Marzo 2017]. Disponible en: http://www.geocities.ws/ciberespao/nuevossuportestecnologicos.doc

MÁRQUEZ, Israel. 2015. Una genealogía de la pantalla: del cine al teléfono móvil, Barcelona: Anagrama.

VALÉRY, Paul. 1999. Piezas sobre arte, Madrid: Visor.

VIRILIO, Paul; LOTRINGER, Sylvère. 2008. Pure War, New York: Semiotext(e). 